\title{
Article \\ Effect of a New Tele-Rehabilitation Program versus Standard Rehabilitation in Patients with Chronic Obstructive Pulmonary Disease
}

\author{
Jose Cerdán-de-las-Heras ${ }^{1,2, *(\mathbb{D})}$, Fernanda Balbino ${ }^{2}$, Anders Løkke ${ }^{3}$, Daniel Catalán-Matamoros ${ }^{4,5}$, \\ Ole Hilberg ${ }^{3}$ and Elisabeth Bendstrup ${ }^{1}$ (D) \\ 1 Department of Respiratory Diseases and Allergy, Center for Rare Lung Diseases, Aarhus University Hospital, \\ 8200 Aarhus, Denmark; karbends@rm.dk \\ 2 Department of Research and Development, Physio R\&D ApS, 2000 Frederiksberg, Denmark; \\ fernanda@physiord.com \\ 3 Department of Respiratory Medicine, Vejle Hospital, 7100 Vejle, Denmark; aloekke@gmail.com (A.L.); \\ ole.hilberg@rsyd.dk (O.H.) \\ 4 Department of Communication and Media Studies, UC3M Medialab, Madrid University Carlos III, \\ 28903 Madrid, Spain; dacatala@hum.uc3m.es \\ 5 Health Research Centre, University of Almeria, 04120 Almeria, Spain \\ * Correspondence: joscer@clin.au.dk; Tel.: +45-30-64-82-83
}

Citation: Cerdán-de-las-Heras, J.; Balbino, F.; Løkke, A.;

Catalán-Matamoros, D.; Hilberg, O. Bendstrup, E. Effect of a New Tele-Rehabilitation Program versus Standard Rehabilitation in Patients with Chronic Obstructive Pulmonary Disease. J. Clin. Med. 2022, 11, 11. https://doi.org/10.3390/jcm11010011

Academic Editors: Sukhwinder Singh Sohal and Emmanuel Andrès

Received: 11 October 2021

Accepted: 16 December 2021

Published: 21 December 2021

Publisher's Note: MDPI stays neutral with regard to jurisdictional claims in published maps and institutional affiliations.

Copyright: (C) 2021 by the authors. Licensee MDPI, Basel, Switzerland. This article is an open access article distributed under the terms and conditions of the Creative Commons Attribution (CC BY) license (https:// creativecommons.org/licenses/by/ $4.0 /)$.

\begin{abstract}
In chronic obstructive pulmonary disease (COPD), rehabilitation is recommended, but attendance rates are low. Tele-rehabilitation may be key. We evaluate the effect of a tele-rehabilitation program vs. standard rehabilitation on COPD. A randomized, non-inferiority study comparing eight weeks of tele-rehabilitation (physiotherapist video/chat-consultations and workout sessions with a virtual-autonomous-physiotherapist-agent (VAPA)) and standard rehabilitation in stable patients with COPD. At baseline, after 8 weeks and 3 and 6 months of follow-up, 6 min walk test distance (6MWTD), 7-day pedometry, quality of life, exercise tolerance, adherence, patient satisfaction and safety were assessed. Fifty-four patients (70 \pm 9 years, male 57\%, FEV1\% $34.53 \pm 11.67$, FVC\% $68.8 \pm 18.81,6$ MWT $376.23 \pm 92.02)$ were included. Twenty-seven patients were randomized to tele-rehabilitation. Non-inferiority in $\triangle 6 \mathrm{MWTD}$ at 8 weeks $(47.4 \pm 31.4)$, and at $3(56.0 \pm 38.0)$ and $6(95.2 \pm 47.1)$ months follow-up, was observed. No significant difference was observed in 7-day pedometry or quality of life. In the intervention group, 6MWTD increased by $25 \%$ and $66 \%$ at 3 and 6 months, respectively; adherence was $81 \%$; and patient satisfaction was $4.27 \pm 0.77$ (Likert scale $0-5$ ). Non-inferiority between groups and high adherence, patient satisfaction and safety in the intervention group were found after rehabilitation and at 3 and 6 months of follow-up. Tele-rehabilitation with VAPA seems to be a promising alternative.
\end{abstract}

Keywords: tele-rehabilitation; COPD; virtual agent

\section{Introduction}

Rehabilitation forms part of the standard treatment in COPD as it improves the quality of life and exercise capacity and reduces symptoms and mortality [1], as well as emergency visits and hospital admissions [2]. Drop-out rates of pulmonary rehabilitation (PR) attendance are high, up to $59 \%$ due to limited motivation $(49.0 \%)$, transportation troubles $(23.8 \%)$, COPD exacerbation (18.4\%), job-related reasons (4.8\%) and hospital admissions $(4.1 \%)[1,3,4]$. The SARS-CoV pandemic has pushed the health sector to a point where new digital procedures to interact with patients need to be rapidly explored, developed and implemented to safely support patient needs [5]. Tele-rehabilitation could be one of the tools to facilitate training for patients with chronic diseases by providing rehabilitation while maintaining physical distance. In a recent review, the usage of tele-rehabilitation in COPD demonstrates potential effectiveness, high patient acceptance and strong motivation to 
engage patients in physical activity [6]. Tele-rehabilitation is a method that is used today to treat, test and follow patients from a distance in order to empower them to cope with their short- and long-term impairments and help them to be physically, mentally, emotionally, vocationally and socially independent, thus improving and maintaining their quality of life. In another review, five different methods of tele-rehabilitation in pulmonary diseases are described: 1-videoconferencing; 2-telephone; 3-using a website with telephone support; 4-using a mobile application; 5-text message support with a mobile app [7]. Tele-rehabilitation was born with the first aim to reduce hospitalization time and to treat patients in rural areas [8], but now, in the COVID-19 pandemic times, it is introduced as an alternative to conventional rehabilitation and as an action to prevent infections and support the continuity of rehabilitation [9-11]. However, tele-rehabilitation in patients with chronic lung diseases and other diseases has not always shown improvements in usability, cost-effectiveness, adherence, safety, and patient and therapist satisfaction, and further research and development to deduct the value of tele-rehabilitation is needed. Focus group interviews have suggested combining face-to-face consultations with userfriendly platforms $[12,13]$. Previously, tele-rehabilitation has been shown to be feasible and positively accepted by patients and to improve functional capacity, breathlessness, quality of life and physical activity [14]. However, patients perceived the technology used as difficult [15-19]. The interaction between patients with COPD at home and the healthcare professionals at the hospital through tele-rehabilitation has developed as a dialogue forming the basis for collective learning processes and new relationships [20]. Previous studies on tele-rehabilitation initiatives in Scotland have shown tele-rehabilitation to be more cost-effective for patients living in distant areas compared to outreach or centralized models [21]. However, there is still a need of studies on new technologies and on the efficacy, cost-effectiveness and long-term benefits of tele-rehabilitation. The aim of this randomized, non-inferiority study was to compare a tele-rehabilitation platform based on virtual agent technology with standard rehabilitation in patients with COPD. The focus of this study is to use tele-rehabilitation as a tool to remotely treat COPD patients.

\section{Methods and Materials}

\subsection{Design of the Research}

The study was performed as a prospective, single-center, non-inferiority randomized, prospective clinical study comparing standard rehabilitation in patients with COPD with tele-rehabilitation. Randomization was performed digitally at www.randomization.com (accessed on 19 January 2017) [22] with subjects randomized into one block (reproducible using seed 9194). The protocol for the study was approved by the Danish Data Protection Agency (reference 2012-58-006) and the Central Denmark Region Committee on Health Research Ethics (reference 1-16-02-417-16). The trial was registered at clinicaltrial.gov (ID NCT03569384). The different objective tests were executed by an independent research nurse not involved in the study.

\subsection{Participants}

Patients with spirometry and physician-verified COPD from the outpatient clinic of the Department of Respiratory Diseases and Allergy, Aarhus University Hospital, Denmark, were randomized if they: (1) were $>18$ years of age, (2) had been referred for standard rehabilitation and (3) signed an informed consent form. Musculoskeletal abnormalities, dizziness, substantial sensory or motor impairments, dementia and/or severe comorbidities that impeded training were all exclusion factors (Supplementary Materials, report 1). Oxygen therapy was not an exclusion criterion.

\subsection{Tele-Rehabilitation}

Patients were randomized 1:1 to 8 weeks of standard or tele-rehabilitation [23]. During follow-up, patients in the intervention group were provided with the opportunity to use a Virtual Autonomous Physiotherapist Agent (VAPA) on a daily basis without the 
supervision of a physiotherapist. At the start of the study, upon the completion of rehabilitation, and after three and six months of follow-up, relevant clinical parameters were collected. Tele-rehabilitation was delivered with VAPA, a Eurostars-funded platform built by a European collaboration (Physio R\&D and Cortrium, Copenhagen, Denmark, and bookBeo, Le Faou, France and Laster Technologies, Paris, France) and two university hospitals (Aarhus University Hospital, Denmark, and Oulu University Hospital, Finland) [24]. The tele-rehabilitation program was originally developed based on feedback from patients with chronic cardiopulmonary diseases [12,13]. VAPA is both (a) a multidisciplinary software that allows therapists to design tailored tele-rehabilitation programs for patients by combining video consultations, e-learning packages, physical training regimens, online questionnaires, patient digital files and direct chat with patients all in one application [25] and (b) a mobile app that can be installed in smartphones or tablets connected directly to a biometric sensor attachable to the chest, arm or finger of the patient to collect data and adjust the rehabilitation program in real time (Figure 1) [26]. Table 1 summarizes the content of the tele-rehabilitation program.

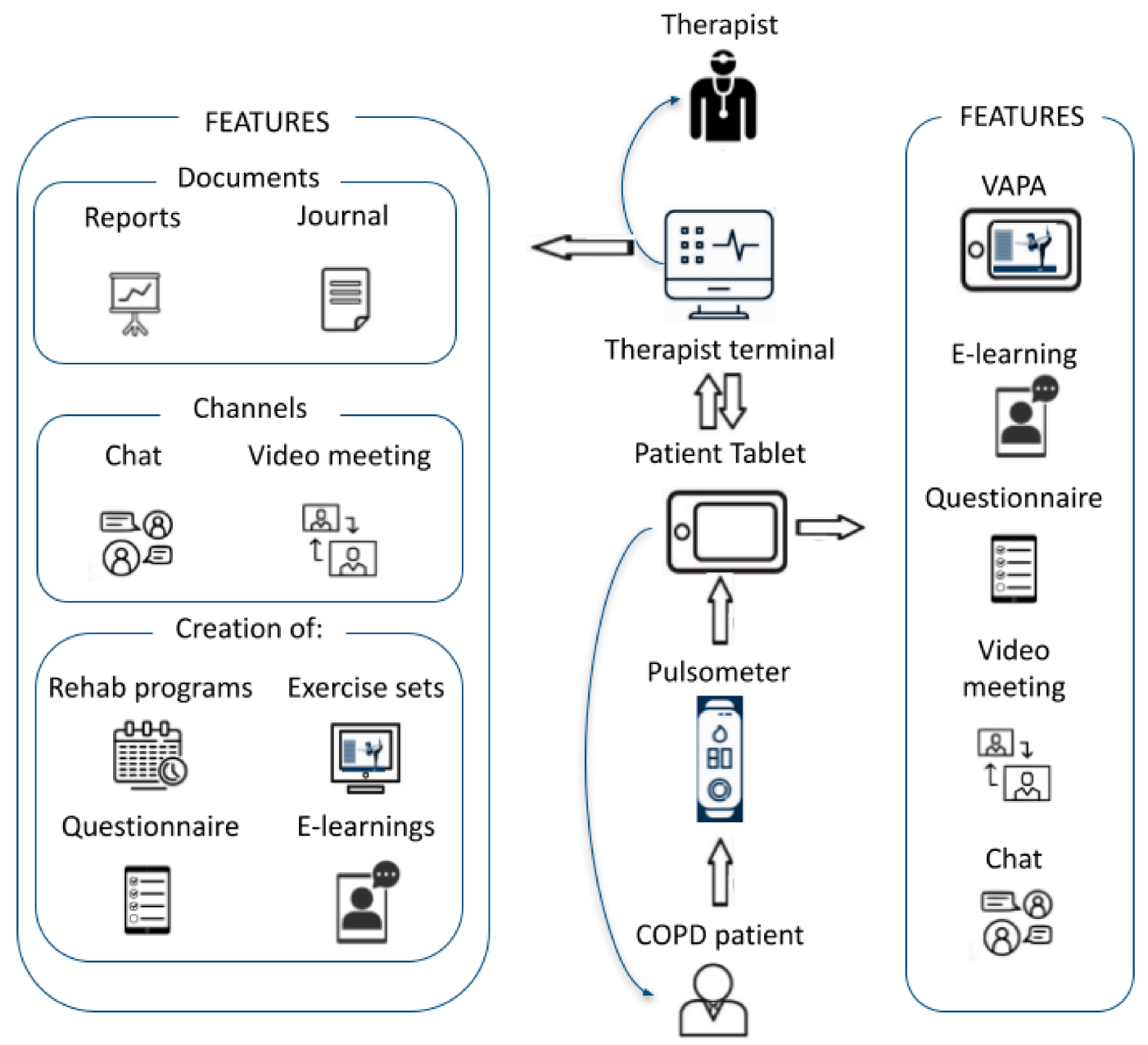

Figure 1. The multifaceted VAPA platform and its digital environment (from Cerdan et al. [27]) (Figure 1 is taken from the paper "Tele-Rehabilitation Program in Idiopathic Pulmonary Fibrosis-A Single-Center Randomized Trial by Cerdan-de-las-heras et al. [27], used under CC BY [28]/content modified from original). 
Table 1. The tele-rehabilitation program. (from Cerdan et al.). (Table 1 is taken from the paper

“Tele-Rehabilitation Program in Idiopathic Pulmonary Fibrosis-A Single-Center Randomized Trial by Cerdan-de-las-heras et al. [27], used under CC BY [28]/content modified from original).

\section{Features}

Workout Sessions with VAPA

E-Learning Packages

Questionnaires

Video Consultation Sessions

Chat Sessions
Explanation

The patients trained 10-20 min 3-5 times a week at home with their individual and tailored VAPA using training aids, such as elastics, weights and a fitness step, to reach the highest workout intensity. The VAPA provided encouragement to continue training during the workout based on a decision support system collecting real time data from a biometric sensor attached to the patient's chest. The decision support system follows, in real time, heart rate data tracked by a biometric sensor attached to the chest of the patient, and according to different parameters, such as age, gender and medication, adjusts the training intensity with easy-difficult exercises used in hospital-based rehabilitation, adapted for home-base execution and stimulating the patient's aerobic-anaerobic workout.

The patient had access to e-learning packages addressing psychological, medical, nutritional and physical aspects of COPD-in part supplied by relevant special data sources medicin.dk [29], lunge.dk [30] and helbredsprofilen.dk. [31], or created by dietitian students after in-depth interviews with pulmonary patients [32-35].

The patients filled out questionnaires regarding satisfaction, breathlessness, and adverse events reporting.

Each patient met the physiotherapist in a video consultation to plan the rehabilitation program and to evaluate previous training experience.

Allowed the patient to interact with and obtain prompt answers from the physiotherapist.

\subsection{Standard Rehabilitation}

In the standard rehabilitation group, patients with COPD underwent a conventional standardized rehabilitation program, as implemented at Aarhus University Hospital. Patients attended 2 weekly group training sessions of $1 \mathrm{~h}$ at the hospital with instruction by a physiotherapist and $6 \mathrm{~h}$ of education about COPD and its treatment for 8 weeks [36].

\subsection{Endpoints}

The primary endpoint was the difference between groups in the 6 min walk test distance (6MWTD) [37] from baseline to the completion of rehabilitation. The secondary endpoints were differences between groups from baseline to follow-up three and six months after the end of rehabilitation in the following: 6MWTD, ActiGraph Monitor wGT3XBT tracked pedometry for 7 days, counting the number of steps taken and total vector magnitude counts per minute (VMCPM) [38]. Patient-reported outcomes were recorded by the St. George's Respiratory Questionnaire, which was used to measure the quality of life (SGRQ) [39], Instrumental Activity of Daily Living (IADL) [40] and the General Anxiety Disorder Score (GAD7) [41]. A pulmonary function test collected information about the forced expiratory volume in the first second (FEV1) and forced vital capacity (FVC). Patients randomly assigned to VAPA tele-rehabilitation rated their satisfaction with the treatment by answering a question on a 5-point Likert scale (1: "very unsatisfied" to 5: "very satisfied") every time they trained. To calculate adherence, the training time per exercise set performed and the weekly average training time were recorded. This was compared to the shortest training time per week shown to be satisfactory for COPD patients. A minimum training duration of $60 \mathrm{~min}$ per week was set as the goal [42].

\subsection{Statistics}

The primary endpoint is based on a minimally important clinical difference of $35 \mathrm{~m}$ in the 6 MWT distance [43]. A 30\% drop-out rate was anticipated [44]. Thus, a total of 54 patients (1:1 ratio) were recruited; 27 patients were enrolled in each group. This sample size allows the estimation of a $95 \%$ confidence interval bound to perform the non-inferiority test with $80 \%$ test power and 0.4 effect size. We decided to use a two-sided independent 
t-test to analyze the secondary endpoints because 1 . It is a robust test even with no normal distribution; 2. We did not find any outliers; 3. There was no previous hypothesis on the direction of the effects for the secondary endpoints; and 4. We expected a substantial number of dropouts potentially preventing the use of an analysis of variance (ANOVA). $R$ and IBM SPSS Statistics version 25 were used to conduct the statistical analysis. According to their randomized treatment group, all patients' results were analyzed, regardless of their adherence to or the received intended treatment, characterizing the use of the intention-totreat approach [45].

\section{Results}

\subsection{Patients}

A total of 95 COPD patients were screened, with 54 of them being enrolled in the study. The baseline demographics of eligible patients who declined to participate were similar to those who were included. Fifty-four patients with COPD were included from March 2017 to March 2019; 27 patients were randomized to standard rehabilitation and 27 to tele-rehabilitation with VAPA (Figure 2). Reasons for dropout are expressed in report 2 in the Supplementary Material. Gender distribution was equal in the two groups, but in the tele-rehabilitation group, patients were younger; more were ever-smokers; and they had, to some extent, a better quality of life (Table 2).

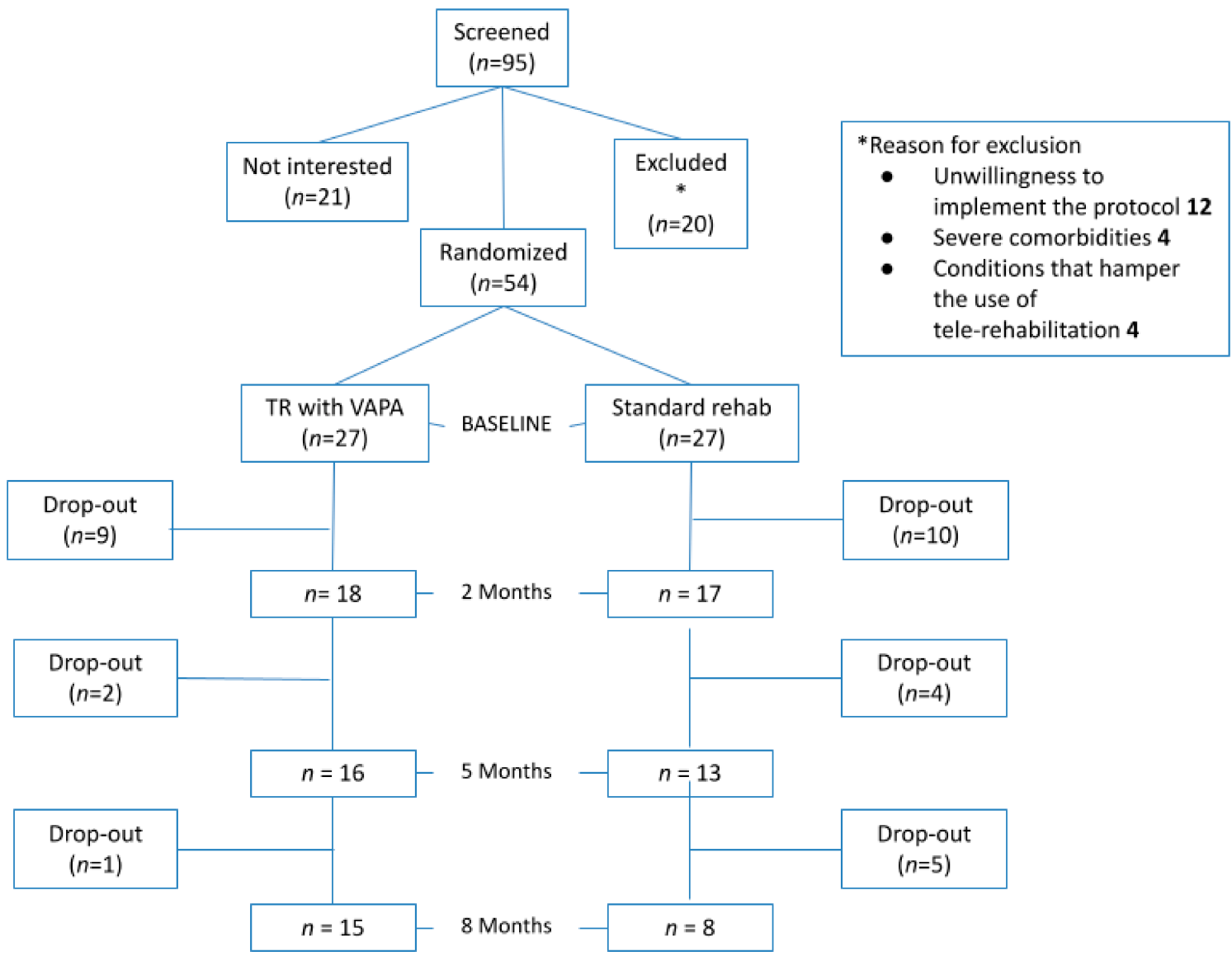

Figure 2. Randomization and enrollment in the general population. 
Table 2. Demographics of the 54 patients that took part in the trial at baseline.

\begin{tabular}{|c|c|c|c|}
\hline Parameters & TR with VAPA $n=27$ & Standard Rehab $n=27$ & $p$ \\
\hline Male, $n(\%)$ & $16(51.6)$ & $15(48.4)$ & - \\
\hline Age (years) * & $67.4(10.2)$ & $72.5(7.4)$ & 0.04 \\
\hline \multicolumn{4}{|l|}{ Smoking Status $\S$} \\
\hline Current, n(\%) & $4(16)$ & $3(14.3)$ & - \\
\hline Former, $n(\%)$ & $21(84)$ & $18(85.7)$ & - \\
\hline Never, $n(\%)$ & $0(0)$ & $0(0)$ & - \\
\hline $\begin{array}{l}\text { Long-Term Oxygen } \\
\text { Therapy, } n(\%)\end{array}$ & $2(7.4 \%)$ & $2(7.4 \%)$ & - \\
\hline FVC $(\%$ predicted $) *$ & $67.4(19.9)$ & $70.2(17.9)$ & 0.60 \\
\hline FEV1 $(\%$ predicted $) *$ & $36.1(14.1)$ & $32.8(8.5)$ & 0.31 \\
\hline $\begin{array}{l}\text { FEV1 Ratio }(\% \\
\text { predicted) } *\end{array}$ & $48.6(15.4)$ & $39.1(17.5)$ & 0.04 \\
\hline 6MWTD $(\mathrm{m})^{*}$ & $385.5(86.9)$ & $366.6(97.8)$ & 0.46 \\
\hline 7-Day Pedometry * & 8601 (4831) & 9234 (7126). & 0.71 \\
\hline $7 \mathrm{dVMCPM} *$ & $282.1(133)$ & $358.3(262)$ & 0.19 \\
\hline SGRQ total * & $55.6(13.5)$ & $60.6(14.1)$ & 0.03 \\
\hline SGRQ, Symptoms * & $56.15(21.1)$ & $61.2(23.5)$ & 0.85 \\
\hline SGRQ, Activity * & 77.5 (14.35) & $76.8(15.4)$ & 0.05 \\
\hline SGRQ, Impact * & $42.8(15.5)$ & $51.2(15.9)$ & 0.18 \\
\hline IADL * & $1.1(1.1)$ & $2.2(2.3)$ & 0.46 \\
\hline GAD7 * & $3.3(3.9)$ & $5.9(6.6)$ & 0.41 \\
\hline
\end{tabular}

* Mean (SD); ${ }^{\circledR}$ missing smoking journal status of 8 patients; FVC: forced vital capacity; FEV1: forced expiratory volume in the first second; 6MWTD: distance walked during the 6 min walk test; 7dVMCPM: 7-day vector magnitude counts per minute; SGRQ: Saint George Respiratory Questionnaire; IADL SCORE: Instrumental Activities of Daily Living Scale; GAD7: General Anxiety Disorder-7 Questionnaire.

\subsection{Min Walk Test (6MWT)}

In the $6 \mathrm{MWT}$, patients receiving the normal hospital rehabilitation and those who received tele-rehabilitation with VAPA walked 387 and $434 \mathrm{~m}$ after 8 weeks of training, respectively, corresponding to a statistically non-significant difference of $47 \mathrm{~m}$ in favor of tele-rehabilitation with VAPA $(p=0.14)$. Mean differences between groups and confidence intervals were calculated (Supplementary report 3, 4 and 5), and the $35 \mathrm{~m}$ non-inferiority margin for the 6MWT was not crossed between baseline and after 8 weeks of rehabilitation and after 3 and 6 months of follow-up (Figure 3).

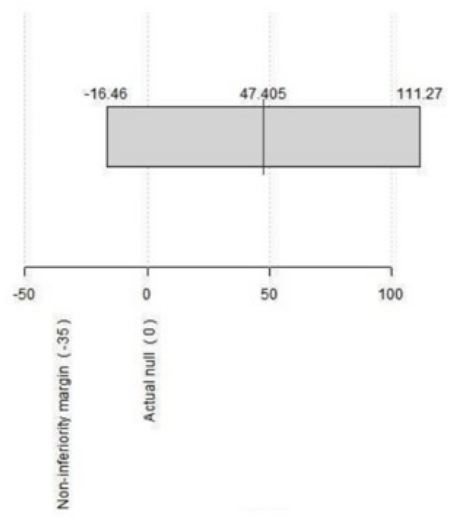

$8 \mathrm{~W}$

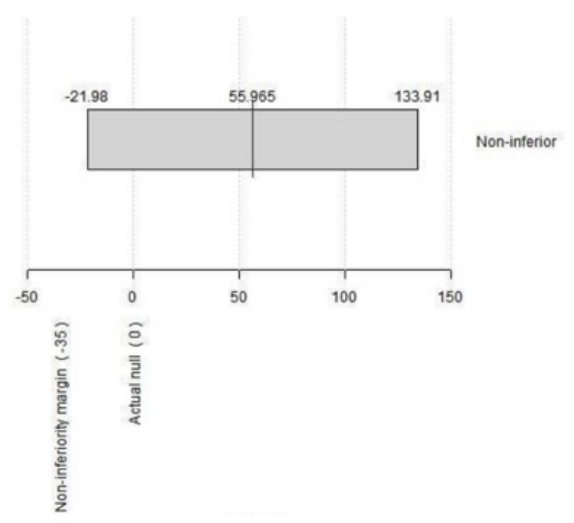

|3M follow-up

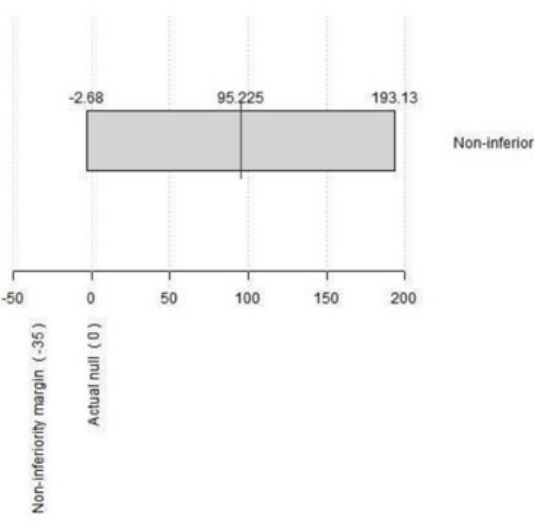

$6 \mathrm{M}$ follow-up

Figure 3. Non-inferiority test regarding the $6 \mathrm{~min}$ walk test distance between baseline and after 8 weeks of rehabilitation and after 3 and 6 months of follow-up. Data are shown as the mean difference between groups and $95 \%$ confidence intervals. 


\subsection{Pedometry and Quality of Life}

No difference between groups with respect to SGRQ, IADL, GAD7 and 7-day pedometry was found (Supplementary report 4 and 5).

\subsection{Continued Use of VAPA in the TR with VAPA}

Among patients who were randomized to VAPA tele-rehabilitation, ten patients decided to continue training with only the "workout sessions with VAPA" after the first 8 weeks training, and five of them decided to continue training after the 3-month follow-up.

\subsection{Exercise Set Time, Adherence, Patient Satisfaction and Safety}

The exercise set mean time showed a difference of a $4 \mathrm{~min}(+25 \%)$ positive increment from 8 weeks $(n=27 ; 15.82 \pm 8.19)$ to 3 months $(n=10 ; 19.82 \pm 9.01)$ and $10.5 \mathrm{~min}(+66 \%)$ from 8 weeks to 6 months $(n=5 ; 26.31 \pm 9.23)$. Overall, adherence was $82 \%$. Patient satisfaction using the 5-point Likert scale scored 4.27 (465 answers in total). No adverse events were reported by participants in the tele-rehabilitation with VAPA group during the trial (Supplementary report 8).

\subsection{Additional Results}

Results regarding exclusion criteria (Supplementary Material, report 1); reasons for dropouts (Supplementary Material, report 2); participants vs. non-participants (Supplementary Material, report 3); baseline data (Supplementary Material, report 4); and follow-up data (Supplementary Material, report 5); confidence interval of other variables (Supplementary Material, report 6); non inferiority 8 weeks vs 3- and 6 months follow-up (Supplementary Material, report 7); and exercise time, adherence and patient satisfaction in the telerehabilitation with VAPA group (Supplementary Material, report 8).

\section{Discussion}

The current study assessed VAPA, a new digital platform for tele-rehabilitation in COPD patients as an alternative to hospital-based rehabilitation. VAPA tele-rehabilitation was found to be non-inferior to traditional hospital rehabilitation in terms of sustained exercise capacity, and patient exercise tolerance, adherence, and satisfaction, and there were no safety issues. With respect to exercise capacity, tele-rehabilitation was non-inferior compared to standard rehabilitation based on the minimal important clinical difference of $35 \mathrm{~m}$ in the 6MWT endpoints [43]. During follow-up, however, we noticed a numerical trend toward improved performance with tele-rehabilitation with VAPA compared to traditional rehabilitation, though it was not statistically significant. Patients who were randomly assigned to the VAPA tele-rehabilitation program experienced an increase in training time at the follow-up visits, as also observed by Vogiatzis et al. [46].

Previous tele-rehabilitation studies in COPD $[15,16]$ have failed to show the superiority of tele-rehabilitation compared to rehabilitation using a videoconference-based platform and group tele-training. In these studies, it was expected that patients allocated to the intervention group would train more often compared to those in the standard rehabilitation group, which could not be demonstrated. Therefore, our study was designed to show non-inferiority between VAPA tele-rehabilitation and standard rehabilitation.

We found no statistical difference in 7-day pedometry or VMCPM between groups or over time in each group, although we saw a trend towards better performance with standard rehabilitation. This may in part be inherent in that patients in the control group had to visit the hospital twice a week during the first part of the trial. However, their pedometry data decreased at a similar pace compared to VAPA tele-rehabilitation. The large standard deviation in both groups may be explained in part by the number of patients and the fact that patients began the research at different seasons of the year, since patients entered during the summer may have walked more than those enrolled during the winter.

We tried to digitize as much of the rehabilitation program's information as feasible at VAPA and combined exercise training with empowering e-learning packages on how 
to live with COPD. There was no statistically significant difference between the groups in terms of QoL, i.e., the impact of digital e-learning and training was non-inferior to standard rehabilitation. These results suggest that the approach executed with e-learning was successful.

There are a variety of technologies and tele-rehabilitation platforms to choose from. The majority rely on videoconferencing, with one or more patients practicing in real time with a therapist, or virtual reality technologies, with agents demonstrating the exercises $[17,25]$. Patients can stay at home and meet electronically using video platforms such as those used in prior trials [15-19].

The aim of this technique is to allow patients to engage in pulmonary rehabilitation in the hospital rehabilitation unit over the internet. The second aim is to maintain telemediated training as a social event similar to meeting face-to-face at the hospital. The intention is to support the social needs of patients training in a virtual group similar to group training in standard rehabilitation programs. Patients benefit from this setup since they can train at home, but training is still planned at specific times, exactly like in the hospital setting, making it less flexible than the VAPA platform. In contrast to VAPA, where patients can train whenever they choose, patients must still schedule their day and energies around the training appointment [18]. It is unclear whether a lack of socialization with other patients has an impact on QoL. Patients who trained with a "agent tele-rehabilitation set-up" in our study continued to train with VAPA more frequently and for longer periods of time in the follow-up phase, thus potentially maximizing the benefits of the treatment [47]. In our study, patient adherence was moderate to high (82\%) and far more than the $20-50 \%$ found in earlier investigations $[47,48]$. Patient satisfaction was rated as very good and similar to the findings of other investigations [14]. VAPA has the capacity to match the exercise intensity to the patient's pulse in real time and guide the thresholds during each exercise session, and this may account for the greater beneficial behavioral improvements observed with VAPA. In accordance with previous studies [49], no adverse events were reported.

The patient drop-out rate in tele-rehabilitation with VAPA was lower than in the standard rehabilitation group but similar to the dropout rate that Sohanpal et al. found in their review on self-management support programs for COPD patients [3].

There are several strengths of our study, including the randomized design and the long-term follow-up. Our study also has several limitations. The power calculations based on 6MWT do not allow the calculation of non-inferiority for the secondary parameters. The high drop-out rate, which is potentially attributable to a lack of commitment and 9transportation issues in standard rehabilitation and the small number of randomized participants that may have caused participants receiving tele-rehabilitation with VAPA to be younger, may have impacted the results. Patients with severe and advanced disease, on the other hand, are more likely to drop out, and our drop-out percentage is comparable to that reported in rehabilitation programs for patients with other chronic respiratory disorders [50,51].

\section{Conclusions}

Tele-rehabilitation with VAPA is non-inferior with respect to exercise capacity in patients with COPD when compared to a standard 8-week rehabilitation program. Telerehabilitation patients had a relatively high exercise time, high adherence and high patient satisfaction, and participation was without risk. Tele-rehabilitation with VAPA is a viable alternative rehabilitation approach for COPD patients, as well as a potentially effective tool for increasing COPD positive behavioral change toward a more physically active lifestyle.

Supplementary Materials: The following are available online at https:/ / www.mdpi.com/article / 10.3390/jcm11010011/s1. Report 1 (exclusion criteria); Report 2 (Reasons for dropout); Report 3 (Participants non participants): Table S1. Baseline parameters between participants and nonparticipants; Report 4 (Baseline data): Table S2 Baseline data of all randomized patients, Table S3: Baseline demographics in the control and intervention group; Report 5 (Follow-up data): Table S4. Data at follow-up after 8 weeks of training, Figure S1. Mean difference and 95\% CI for 6MWT between 
patients in the control and TR with VAPA groups after 8 weeks of training, Table S5. Data at follow-up three months after completion of training, Figure S2. Mean difference and 95\% CI for 6MWT between patients in the control and TR with VAPA groups, 3 months after completion of training, Table S6. Data at follow-up six months after completion of training, Figure S3. Mean difference and 95\% CI for 6MWT between patients in the control and TR with VAPA groups, 6 months after completion of training, Figure S4. Mean and Standard Deviation for the 6 min walking test over time for patients in the control and intervention group (meters), Figure S5. Mean and Standard Deviation for the 7 days pedometer over time for patients in the control and intervention group (meters), Figure S6. Mean and Standard Deviation for the $7 \mathrm{dVMCPM}$ over time for patients in the control and intervention group (meters), Figure S7. Mean and Standard Deviation for the pulmonary function FVC\% over time for patients in the control and intervention group (percentage), Figure S8. Mean and Standard Deviation for the pulmonary function FVE1\% over time for patients in the control and intervention group (percentage), Figure S9. Mean and Standard Deviation for the pulmonary function FVE1/FVC ratio over time for patients in the control and intervention group (percentage), Figure S10. Mean and Standard Deviation for the SGQR over time for patients in the control and intervention group, Figure S11. Mean and Standard Deviation for GAD-7 over time for patients in the control and intervention group, Figure S12. Mean and Standard Deviation for the Instrumental Activities Of Daily Living Scale over time for patients in the control and intervention group, Figure S13. Mean and Standard Deviation for the $4 \mathrm{~m}$ gait test over time for patients in the control and intervention group, Table S7: Analysis of changes over time in pulmonary function, physical performance, physical activity, exercise recovery and quality of life in the control group, Table S8: Analysis of changes over time in pulmonary function, physical performance, physical activity, exercise recovery and quality of life in the intervention group; Report 6 (Confidence interval of other variables): Table S9: Quality of life differences between groups in each evaluation, Table S10: Seven days pedometry and vector magnitude counts per minute differences between groups at each follow-up; Report 7 (Non inferiority 8 weeks vs 3- and 6 months follow-up): Table S11. Three months follow-up difference after treatment, Table S12. Six months follow-up difference after treatment; Report 8 (Exercise Time, Adherence and Patient Satisfaction in the Telerehabilitation with VAPA group): Figure S14: Exercise time by patients in the TR with VAPA, Table S13: Patient adherence and satisfaction shown as the training time expected vs performed and patient satisfaction from baseline to follow-up after 8 months.

Author Contributions: Conceptualization, funding acquisition and project administration, J.C.-d.-1.-H., E.B. and O.H.; methodology J.C.-d.-1.-H., F.B., E.B. and O.H.; data curation, J.C.-d.-1.-H. and F.B.; formal analysis and writing-original draft preparation, J.C.-d.-1.-H., E.B., D.C.-M., E.B., A.L. and O.H.; visualization, J.C.-d.-l.-H., F.B., D.C.-M., E.B., A.L. and O.H. All authors have read and agreed to the published version of the manuscript.

Funding: EUROSTARS grant number E10287 and Aarhus University grant number 18226975 were used to fund this study.

Institutional Review Board Statement: The study was carried out in accordance with the Declaration of Helsinki principles and was approved by the Central Denmark Region Committee on Health Research Ethics (ref: 1-16-02-417-16), as well as the Danish Data Protection Agency (ref: 2012-58-006). The trial was registered with Clinicaltrials.gov (ID NCT03569384).

Informed Consent Statement: All of the participants in the study gave their informed consent.

Data Availability Statement: Data are contained within the article or Supplementary Materials.

Acknowledgments: Thank you to all of the COPD patients who came to our center and were interested in learning more about our research project or participating in our clinical study, as well as their family members who helped participants keep track of their training or planned follow-up. Thank you to everyone at Aarhus University Hospital's Department of Respiratory Diseases and Allergy for helping to create the ideal setting, as well as organizing follow-ups and, in many cases, offering an extra hand to assist the participants in a variety of scenarios.

Conflicts of Interest: J.C.H. is PhD student at Aarhus University Hospital, as well as a founder of Physio R\&D limited company, who has designed and developed the Virtual Autonomous Physiotherapist Agent used in this trial. E.B., O.H., A.L., F.B. and D.C.-M. declare no conflicts of interest. 


\section{References}

1. Sundhedsstyrelsen. Resumé Af Anbefalinger for KOL. 2007, Volume 28. Available online: sundhedsstyrelsen.dk/publ/Publ2007/ CFF/KOL/KOLanbefalinger-resume.pdf (accessed on 30 January 2021).

2. Lawlor, M.; Kealy, S.; Agnew, M.; Korn, B.; Quinn, J.; Cassidy, C.; Silke, B.; O'Connell, F.; O’Donnell, R. Early Discharge Care with Ongoing Follow-up Support May Reduce Hospital Readmissions in COPD. Int. J. Chron. Obstruct. Pulmon. Dis. 2009, 4, 55-60.

3. Sohanpal, R.; Hooper, R.; Hames, R.; Priebe, S.; Taylor, S. Reporting Participation Rates in Studies of Non-Pharmacological Interventions for Patients with Chronic Obstructive Pulmonary Disease: A Systematic Review. Syst. Rev. 2012, 1, 66. [CrossRef]

4. Sahin, H.; Naz, I. Why Are COPD Patients Unable to Complete the Outpatient Pulmonary Rehabilitation Program? Chron. Respir. Dis. 2018, 15, 411-418. [CrossRef] [PubMed]

5. The Differences between SARS-CoV-1 and SARS-CoV-2. Available online: https://sciencemediahub.eu/2020/04/23/thedifferences-between-sars-cov-1-and-sars-cov-2/ (accessed on 30 January 2021).

6. Rutkowski, S. Management Challenges in Chronic Obstructive Pulmonary Disease in the COVID-19 Pandemic: Telehealth and Virtual Reality. J. Clin. Med. Res. 2021, 10, 1261. [CrossRef]

7. Cox, N.S.; Dal Corso, S.; Hansen, H.; McDonald, C.F.; Hill, C.J.; Zanaboni, P.; Alison, J.A.; O’Halloran, P.; Macdonald, H.; Holland, A.E. Telerehabilitation for Chronic Respiratory Disease. Cochrane Database Syst. Rev. 2021, 1, CD013040. [CrossRef]

8. Peretti, A.; Amenta, F.; Tayebati, S.K.; Nittari, G.; Mahdi, S.S. Telerehabilitation: Review of the State-of-the-Art and Areas of Application. JMIR Rehabil Assist Technol 2017, 4, e7511. [CrossRef]

9. Why Is Telerehabilitation so Important during the COVID-19 Pandemic? Available online: https://shrs.uq.edu.au/article/2020 /05/why-telerehabilitation-so-important-during-covid-19-pandemic (accessed on 3 November 2021).

10. Scherrenberg, M.; Frederix, I.; De Sutter, J.; Dendale, P. Use of Cardiac Telerehabilitation during COVID-19 Pandemic in Belgium. Acta Cardiol. 2021, 76, 773-776. [CrossRef]

11. Scherrenberg, M.; Wilhelm, M.; Hansen, D.; Völler, H.; Cornelissen, V.; Frederix, I.; Kemps, H.; Dendale, P. The Future Is Now: A Call for Action for Cardiac Telerehabilitation in the COVID-19 Pandemic from the Secondary Prevention and Rehabilitation Section of the European Association of Preventive Cardiology. Eur. J. Prev. Cardiol. 2021, 28, 524-540. [CrossRef]

12. de Las Heras, J.C.; Tulppo, M.; Kiviniemi, A.M.; Hilberg, O.; Løkke, A.; Ekholm, S.; Catalán-Matamoros, D.; Bendstrup, E. Augmented Reality Glasses as a New Tele-Rehabilitation Tool for Home Use: Patients' Perception and Expectations. Disabil. Rehabil. Assist. Technol. 2020, 1-7. [CrossRef]

13. Cerdan, J.; Catalan-Matamoros, D.; Berg, S.W. Online Communication in a Rehabilitation Setting: Experiences of Patients with Chronic Conditions Using a Web Portal in Denmark. Patient Educ. Couns. 2017, 100, 2283-2289. [CrossRef]

14. Paneroni, M.; Colombo, F.; Papalia, A.; Colitta, A.; Borghi, G.; Saleri, M.; Cabiaglia, A.; Azzalini, E.; Vitacca, M. Is Telerehabilitation a Safe and Viable Option for Patients with COPD? A Feasibility Study. COPD: J. Chronic Obstr. Pulm. Dis. 2015, 12, 217-225. [CrossRef]

15. Hansen, H.; Bieler, T.; Beyer, N.; Godtfredsen, N.; Kallemose, T.; Frølich, A. COPD Online-Rehabilitation versus Conventional COPD Rehabilitation-Rationale and Design for a Multicenter Randomized Controlled Trial Study Protocol (CORe Trial). BMC Pulm. Med. 2017, 17, 140. [CrossRef]

16. Hansen, H.; Bieler, T.; Beyer, N.; Kallemose, T.; Wilcke, J.T.; Østergaard, L.M.; Frost Andeassen, H.; Martinez, G.; Lavesen, M.; Frølich, A.; et al. Supervised Pulmonary Tele-Rehabilitation versus Pulmonary Rehabilitation in Severe COPD: A Randomised Multicentre Trial. Thorax 2020, 75, 413-421. [CrossRef]

17. Telehealth: Secure and HIPAA-Compliant-SimplePractice. Available online: https://www.simplepractice.com/telehealth/ (accessed on 30 January 2021).

18. Rayce, K.; Rosenbek Minet, L.; Kidholm, K.; Vestbo, J.; Pedersen, C.D.; Huniche, L. Telemediated Training in the Home as a Part of the Everyday Life and Practice With Very Severe Chronic Obstructive Pulmonary Disease. Qual. Health Res. 2020, 30, $2132-2145$. [CrossRef]

19. Telehealth for Physical Therapy. Available online: https://www.physitrack.com/telehealth (accessed on 30 January 2021).

20. Dinesen, B.; Andersen, S.K.; Hejlesen, O.; Toft, E. Interaction between COPD Patients and Healthcare Professionals in a CrossSector Tele-Rehabilitation Programme. Stud. Health Technol. Inform. 2011, 169, 28-32. [PubMed]

21. Hill, A.; Sppath, B. Telerehabilitation in Scotland: Current Initiatives and Recommendations for Future Development. Int. J. Telerehabilitation 2010, 2, 7-14. [CrossRef] [PubMed]

22. Randomization Plans: Never the Same Thing Twice! Available online: http://www.jerrydallal.com/random/randomize.htm (accessed on 19 January 2017).

23. Bolton, C.E.; Bevan-Smith, E.F.; Blakey, J.D.; Crowe, P.; Elkin, S.L.; Garrod, R.; Greening, N.J.; Heslop, K.; Hull, J.H.; Man, W.D.-C.; et al. British Thoracic Society Guideline on Pulmonary Rehabilitation in Adults: Accredited by NICE. Thorax 2013, 68, ii1-ii30. [CrossRef]

24. VAPA. Available online: https://www.eurostars-eureka.eu/project/id/10287 (accessed on 18 August 2020).

25. Solution. Available online: https:/ / optimov.com/?page_id=3006 (accessed on 20 September 2020).

26. Products-Optimov. Available online: https:/ / optimov.com/?page_id=1879 (accessed on 20 September 2020).

27. Cerdán-de-las-Heras, J.; Balbino, F.; Løkke, A.; Catalán-Matamoros, D.; Hilberg, O.; Bendstrup, E. Tele-Rehabilitation Program in Idiopathic Pulmonary fibrosis-A Single-Center Randomized Trial. Int. J. Environ. Res. Public Health 2021, $18,10016$. 
28. Creative Commons-Attribution 4.0 International-CC BY 4.0. Available online: https://creativecommons.org/licenses/by/4.0/ (accessed on 4 October 2021).

29. Medicin.dk-Information Om Medicin. Available online: http://medicin.dk/ (accessed on 21 August 2020 ).

30. Lungeforeningen. Available online: https://www.lunge.dk/ (accessed on 21 August 2020).

31. Helbredsprofilen.dk. Available online: https://helbredsprofilen.dk/da (accessed on 21 August 2020 ).

32. Spis Rigtigt-Antiinflammatorisk Kost-YouTube. Available online: https://youtube.com/embed/w5fjXI6NHec (accessed on 26 August 2020).

33. Spis Rigtigt-Frugt Og Grønt-YouTube. Available online: https://youtube.com/embed/50479Caonrc (accessed on 26 August 2020).

34. Råd Til Undervægtige-YouTube. Available online: https://youtube.com/embed/t1Haq6Gf5hA (accessed on 26 August 2020).

35. Råd Til Overvægtige-YouTube. Available online: https:/ / youtube.com/embed/UKdjxpVjqFA (accessed on 26 August 2020).

36. Sundhedsstyrelsen. Nationale kliniske retningslinjer for rehabilitering af patienter med KOL (kronisk obstruktiv lungelidelse). Available online: https://www.sst.dk/-/media/Udgivelser/2018/National-Klinisk-Retningslinje-for-Rehabilitering-afpatienter-med-KOL.ashx?la=da\&hash=81976AC77E8FCEF659052AE0A1ED378C18AEAC47 (accessed on 28 February 2021).

37. Holland, A.E.; Spruit, M.A.; Troosters, T.; Puhan, M.A.; Pepin, V.; Saey, D.; McCormack, M.C.; Carlin, B.W.; Sciurba, F.C.; Pitta, F.; et al. An Official European Respiratory Society/American Thoracic Society Technical Standard: Field Walking Tests in Chronic Respiratory Disease. Eur. Respir. J. 2014, 44, 1428-1446. [CrossRef]

38. Hecht, A.; Ma, S.; Porszasz, J.; Casaburi, R. Methodology for Using Long-Term Accelerometry Monitoring to Describe Daily Activity Patterns in COPD the COPD Clinical Research Network. COPD 2009, 2, 121-129. [CrossRef] [PubMed]

39. Jones, P.W.; Quirk, F.H.; Baveystock, C.M. The St George's Respiratory Questionnaire. Respir. Med. 1991, 85 (Suppl. B), 25-31, discussion 33-7. [CrossRef]

40. Lawton, M.P.; Brody, E.M. Assessment of Older People: Self-Maintaining and Instrumental Activities of Daily Living. Gerontologist 1969, 9, 179-186. [CrossRef]

41. Spitzer, R.L.; Kroenke, K.; Williams, J.B.W.; Löwe, B. A Brief Measure for Assessing Generalized Anxiety Disorder: The GAD-7. Arch. Intern. Med. 2006, 166, 1092-1097. [CrossRef]

42. Burge, A.T.; Cox, N.S.; Abramson, M.J.; Holland, A.E. Interventions for Promoting Physical Activity in People with Chronic Obstructive Pulmonary Disease (COPD). Cochrane Database Syst. Rev. 2020, 4, CD012626. [CrossRef]

43. Puhan, M.A.; Mador, M.J.; Held, U.; Goldstein, R.; Guyatt, G.H.; Schünemann, H.J. Interpretation of Treatment Changes in 6-Minute Walk Distance in Patients with COPD. Eur. Respir. J. 2008, 32, 637-643. [CrossRef]

44. Sohanpal, R.; Hooper, R.L.; Hames, R.; Priebe, S.; Taylor, S. S112 Estimating Participation Rates of COPD Patients in Pulmonary Rehabilitation and Self-Management Programmes: The Importance of Defining Participation. Thorax 2012, 67, A55. [CrossRef]

45. McCoy, C.E. Understanding the Intention-to-Treat Principle in Randomized Controlled Trials. West. J. Emerg. Med. 2017, 18, 1075-1078. [CrossRef]

46. Vogiatzis, I.; Nanas, S.; Kastanakis, E.; Georgiadou, O.; Papazahou, O.; Roussos, C. Dynamic Hyperinflation and Tolerance to Interval Exercise in Patients with Advanced COPD. Eur. Respir. J. 2004, 24, 385-390. [CrossRef]

47. Dowman, L.M.; McDonald, C.F.; Hill, C.J.; Lee, A.L.; Barker, K.; Boote, C.; Glaspole, I.; Goh, N.S.L.; Southcott, A.M.; Burge, A.T.; et al. The Evidence of Benefits of Exercise Training in Interstitial Lung Disease: A Randomised Controlled Trial. Thorax 2017, 72, 610-619. [CrossRef]

48. Yuen, H.K.; Lowman, J.D.; Oster, R.A.; de Andrade, J.A. Home-Based Pulmonary Rehabilitation for Patients With Idiopathic Pulmonary Fibrosis: A PILOT STUDY. J. Cardiopulm. Rehabil. Prev. 2019, 39, 281-284. [CrossRef]

49. Yu, X.; Li, X.; Wang, L.; Liu, R.; Xie, Y.; Li, S.; Li, J. Pulmonary Rehabilitation for Exercise Tolerance and Quality of Life in IPF Patients: A Systematic Review and Meta-Analysis. Biomed Res. Int. 2019, 2019, 8498603. [CrossRef] [PubMed]

50. Li, Y.; Qian, H.; Yu, K.; Huang, Y. Nonadherence in Home-Based Pulmonary Rehabilitation Program for COPD Patients. Can. Respir. J. 2020, 2020, 5146765. [CrossRef] [PubMed]

51. Fischer, M.J.; Scharloo, M.; Abbink, J.J.; van 't Hul, A.J.; van Ranst, D.; Rudolphus, A.; Weinman, J.; Rabe, K.F.; Kaptein, A.A. Drop-out and Attendance in Pulmonary Rehabilitation: The Role of Clinical and Psychosocial Variables. Respir. Med. 2009, 103, 1564-1571. [CrossRef] [PubMed] 